\title{
Modification of Caster Oil and Study Its Efficiency as Corrosion Inhibitors in Formation Water Media
}

\author{
Hikmat AbduLRahem Ali \\ Polymer Research Center, Universty of Basra, Basra, Iraq. \\ Email:hakmatali@yahoo.com
}

How to cite this paper: Ali, H.A (2017) Modification of Caster Oil and Study Its Efficiency as Corrosion Inhibitors in Formation Water Media. Engineering, 9, 254262.

https://doi.org/10.4236/eng.2017.93013

Received: February 13, 2017

Accepted: March 28, 2017

Published: March 31, 2017

Copyright $\odot 2017$ by author and Scientific Research Publishing Inc. This work is licensed under the Creative Commons Attribution International License (CC BY 4.0).

http://creativecommons.org/licenses/by/4.0/

\begin{abstract}
The present study relates to preparation corrosion inhibiter from caster oil for carbon steel pipeline by two steps; the first step includes sulfonation of caster oil and the second step includes amination the sulfonic caster oil with ammonia solution the final product characterized by FTIR. The effectiveness of the synthesized compounds is studied as corrosion inhibitors for carbon steel; in formation, water was investigated by electrochemical techniques using Tafel plot methods. The synthesized compounds showed enhancement in inhibition efficiencies, and then studied the effect of temperatures on inhibition efficiency.
\end{abstract}

\section{Keywords}

Modification, Caster Oil, Corrosion Inhibitors

\section{Introduction}

Corrosion is the destructive attack of a material by reaction with its Environment [1]. Corrosion is a chemical or electrochemical oxidation process, in which the metal transfers electrons to the environment and undergoes a valance change from zero to a positive value [2]. The serious consequences of the corrosion process have become a problem of worldwide significance [3]. Corrosion control is achieved by recognizing and understanding corrosion mechanisms, using corrosion inhibitor materials. A corrosion inhibitor is a chemical substance that, when added in small concentration to an environment, effectively decreases the corrosion rate [4]-[9].

The use of chemical inhibitors to decrease the rate of corrosion processes is quite varied. In the oil extraction and processing industries, inhibitors have always been considered to be the first line of defense against corrosion. A great 
number of scientific studies have been devoted to the subject of corrosion inhibitors. However, most of what is known has grown from trial and error experiments, both in the laboratories and in the field. Rules, equations, and theories to guide inhibitor development or use are very limited. Inhibitors have been classified by their chemical functionality into: inorganic inhibitors, organic inhibitors [10]-[16].

Organic inhibitor are applied extensively to protect metals from corrosion in many aggressive acidic media (e.g., in the acid pickling and cleaning process of metals). Different kinds of organic compounds are used as corrosion inhibitors for iron alloys in various acid media such as aromatic compounds with positively charged amine groups, Sodium sulfonates, phosphonates, or mercaptobenzotriazole (MBT) are used commonly in cooling waters and antifreeze solutions [17] [18] [19] [20]. In the present study used ammonium sulfonated castor oil (ASC) to produced water soluble amino compound as corrosion inhibitor.

\section{Experimental Techniques}

\subsection{Material and Instrument}

Caster oil, sulfuric acid, ammonia solution, mechanical stirring, bath, evaporation rotary, viscometer, IR spectra, RP 6000, carbon steel (C1010) standard strips and potentiostat.

\subsection{Experimental Procedure}

\subsubsection{Ammonium Sulfonated Castor Oil (ASC) Preparation}

In a $500 \mathrm{ml}$ three-neck round bottom flask, $250 \mathrm{ml}$ of castor oil and $75 \mathrm{ml}$ of sulfuric acid were charged and the whole were stirred for $24 \mathrm{~h}$ at room temperature. At the end of reaction, the reaction was cooled to room temperature and then, ethyl acetate $(50 \mathrm{~mL})$ was added to the reaction mixture with stirrer for 30 min, followed by filtration to separate the precipitate from the mixture medium. The precipitate obtained was purified by column chromatography (silicagel, petroleum ether/ethyl acetate $(100 / 1, \mathrm{v} / \mathrm{v})$ as eluent) to give sulfonated castor oil (SC). Then the (SC) dissolved in distilled water and neutralized with ammonium solution to give ammonium sulfonated castor oil (ASC) [21] [22] [23] [24].

\subsubsection{Preparing the Metal Specimen for Test}

A standard strip of carbon steel alloy (C1010) is shown in Figure 1 with dimensions of $3 \mathrm{~cm}$ long, $1.24 \mathrm{~cm}$ wide and $0.14 \mathrm{~cm}$ thick. The total area of immersed strip is $8.45 \mathrm{~cm}^{2}$. Carbon steel strips were used to evaluate the prepared compounds as corrosion inhibitors. The faces of each specimen were grinded and polished

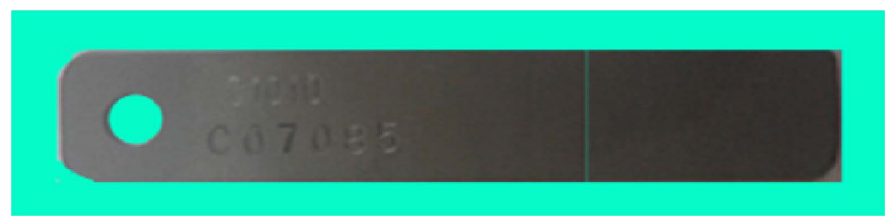

Figure 1. The carbon steel alloy. 
by emery cloth paper to 400 micron. Then specimens degreased with acetone, and are washed with distilled water and ethanol. Hot air were used to dry the sample and stored in a desiccators containing silica gel during the period in between polishing and Tafel measurements. The composition of these alloys was illustrated in Table 1.

\subsubsection{Preparing the Corrosive Environments}

In present study, we use formation water from Iraqi southern oil Company as corrosive environment. The compositional analyses of formation waters carried out in south oil company-Basrah, as shown in Table 2 and Table 3.

\section{Result and Discussion}

\subsection{Characterization of the Ammonium Sulfonated Castor Oil}

The new compounds were characterized, by FTIR Spectroscopy-technique, as a viscous solution by using sodium chloride disc. Spectra [25] [26] are shown in Figure 2 and Figure 3. From IR Spectrum, the SO3 group and N-H group don't give absorption in Figure 2, but they gave absorption in Figure 3 as showed in Table 4.

\subsection{Evaluation of Ammonium Sulfonated Castor Oil as Corrosion Inhibiter}

A potentiostat was used to measure current density vs electric potential in order to calculate the corrosion rates. The electrochemical results obtained from polarization experiments through "Tafel plots" performed in corrosive environment (formation water) in the absence and presence of different specified concentration of (ASC) (from $5 \mathrm{ppm}$ to $30 \mathrm{ppm}$ ) are showed in Figure 4, Figure 5 and Table 5 at constant temperature $26^{\circ} \mathrm{C}$. The Corrosion rate (CR) was measured in $(\mathrm{mm} / \mathrm{y})$ units, and to convert corrosion rate (CR) from (mmy) to (mpy), Equation (1) were used [27]:

$$
\mathrm{CR} / \mathrm{mpy}=0.0254 \mathrm{~mm} / \mathrm{y}
$$

Table 1. Chemical composition of carbon steel alloy.

\begin{tabular}{ccccccccccc}
\hline \multicolumn{1}{c}{ Alloy } & C & Mn & P & S & Si & Ni Cr Cu As & Fe \\
\hline Carbon steel (C1010) & $0.08-0.13$ & $0.3-0.5$ & 0.04 & 0.05 & $0.17-0.37$ & 0.3 & 0.1 & 0.3 & 0.08 & Residue
\end{tabular}

Table 2. Analysis for the formation water.

\begin{tabular}{ccccc}
\hline Total suspended Solid TSS (ppm) & Salinity (ppm) & Conductivity (semen) & TDS (ppm) & $\mathrm{pH}$ \\
\hline 160.8 & 374,000 & $4,340,000$ & 217,000 & 6.6
\end{tabular}

Table 3. Ions concentration ( $\mathrm{ppm}$ ) in formation water.

\begin{tabular}{ccccccc}
\hline $\mathrm{Ca}^{2+}$ & $\mathrm{Mg}^{2+}$ & $\mathrm{Na}^{+}$ & $\mathrm{K}^{+}$ & $\mathrm{Cl}^{-}$ & $\mathrm{HCO}_{3}^{-}$ & $\mathrm{SO}_{4}^{-2}$ \\
\hline 150 & 2975 & 471 & 110 & 11,260 & 82 & 200 \\
\hline
\end{tabular}




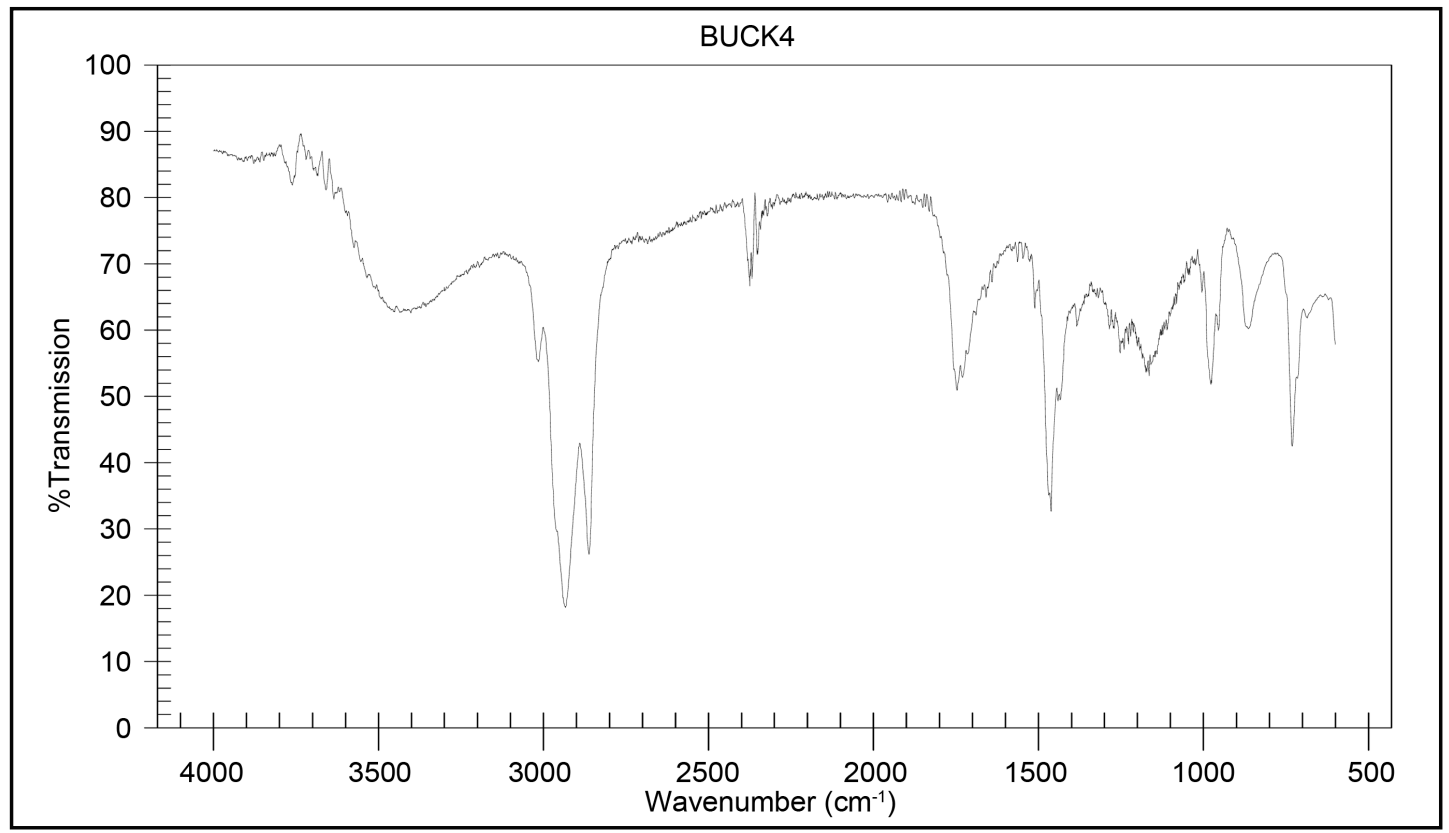

Figure 2. IR Spectra of caster oil.

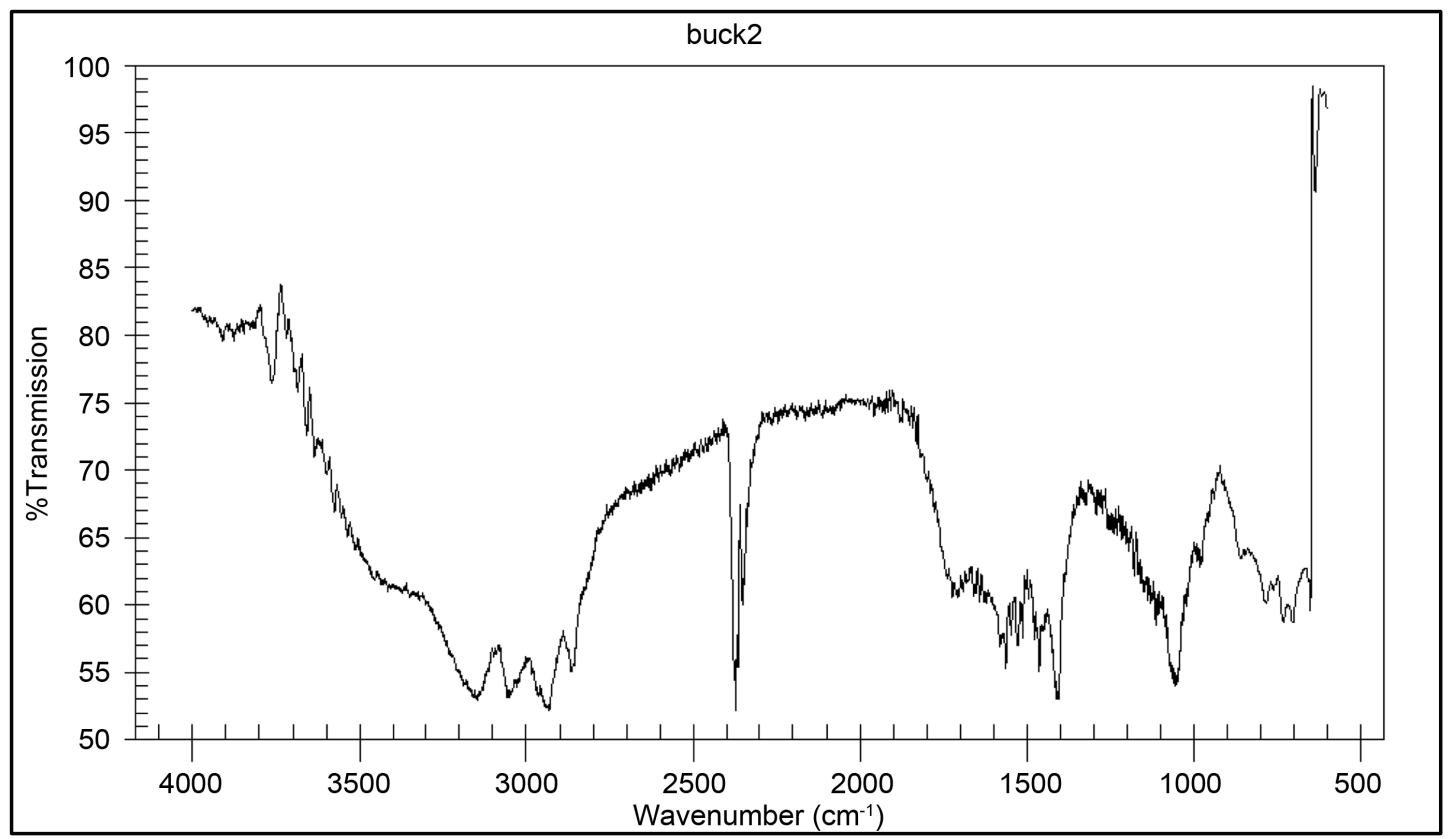

Figure 3. IR spectra of ammonium sulfonated caster oil (ASC).

Table 4. Explain IR spectra for both caster oil and ammonium sulfonated caster oil.

\begin{tabular}{cccccc}
\hline IR spectrum & $\mathrm{CH}_{2}$ abs cm- & $\mathrm{C}-\mathrm{H}$ abs cm- & $\mathrm{SO}_{3}-\mathrm{abs} \mathrm{cm}-$ & $\mathrm{N}-\mathrm{H}$ abs cm- & $-\mathrm{S}$ \\
\hline Caster oil & 2995,2880 & 680,1450 & - & - & - \\
Ammonium Sulfonated Caster oil & 2995,2880 & 680,1450 & 1220,1050 & 315,350 & 1650 \\
\hline
\end{tabular}

Tafel plots employed for rapid evaluation inhibitors in order to determine their effectiveness on the corrosion rates of carbon steel. From Table 5 and Figure 5, the prepared compound (ASC) showed high inhibition efficiency for corrosion 


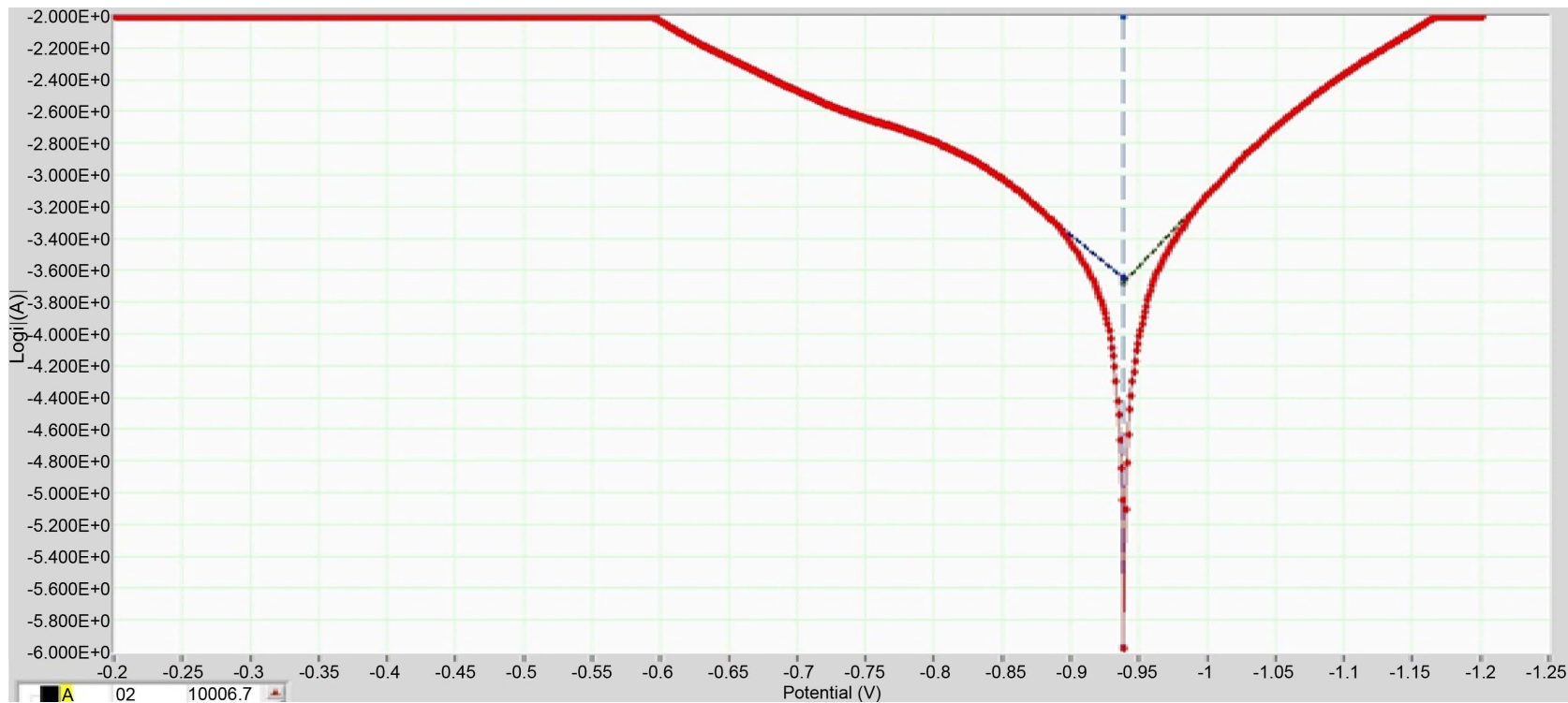

Figure 4. Tafel plot of formation water without inhibitor.

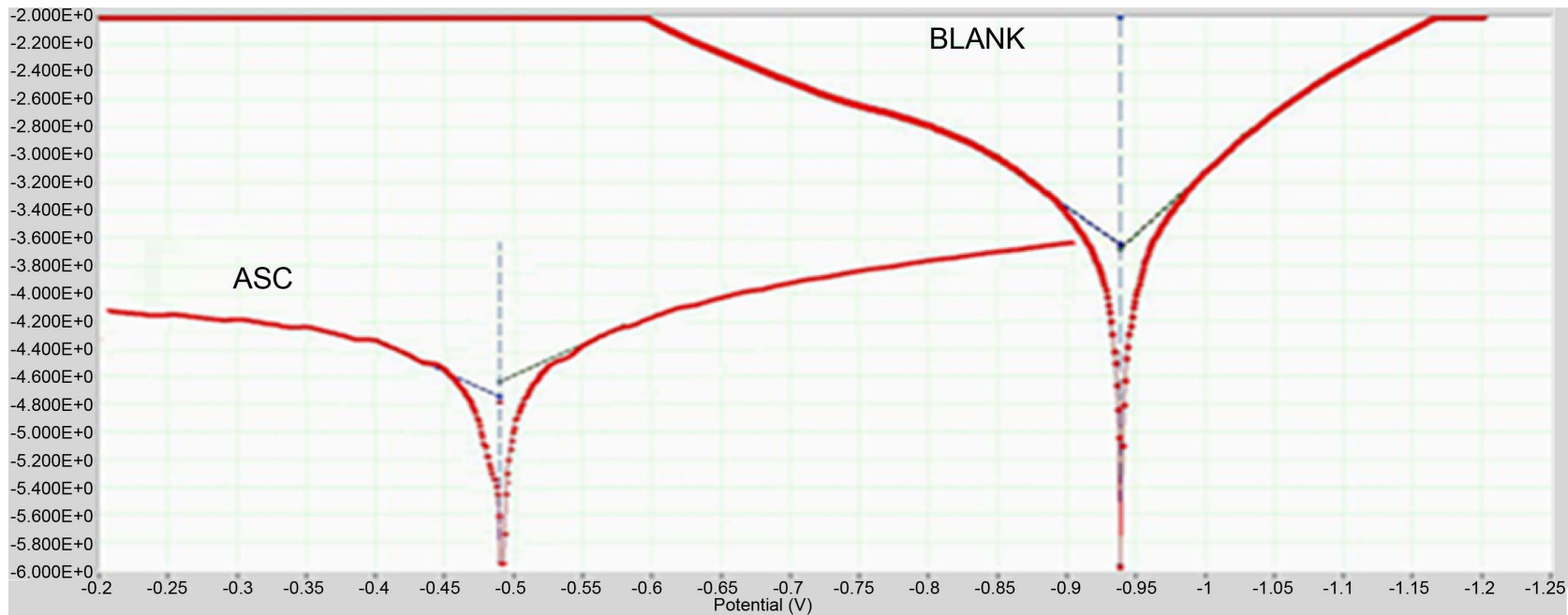

Figure 5. Tafel plot with optimum value $25 \mathrm{ppm}$ of inhibiter (ASC).

Table 5. Corrosion inhibiter for compound (ASC) at constant temperatur $\left(25^{\circ} \mathrm{C}\right)$.

\begin{tabular}{cccccccc}
\hline Conc $(\mathrm{ppm})$ & Ecorr $(\mathrm{V})$ & $\begin{array}{c}\text { Icorr }(\mathrm{A}) \\
\mathrm{E}-6\end{array}$ & $\begin{array}{c}\mathrm{CR}(\mathrm{mm} / \mathrm{year}) \\
\mathrm{E}-3\end{array}$ & $\mathrm{CR}(\mathrm{mpy})$ & $\beta \mathrm{c}(\mathrm{A} / \mathrm{V})$ & $\beta \mathrm{a}(\mathrm{A} / \mathrm{V})$ & $\begin{array}{c}\text { Rct }(\mathrm{ohm}) \\
\mathrm{E}+3\end{array}$ \\
\hline 0 & -0.94 & 224.0 & 241.5 & 9.5078 & -9.191 & 7.117 & 0.1147 \\
5 & -0.5 & 4.468 & 4.818 & 0.1896 & -5.369 & 5.060 & 5.750 \\
10 & -0.44 & 15.09 & 16.28 & 0.6409 & -6.265 & 5.879 & 1.702 \\
15 & -0.44 & 12.89 & 13.90 & 0.5472 & -6.324 & 5.234 & 1.994 \\
20 & -0.44 & 12.65 & 13.64 & 0.5370 & -6.480 & 5.208 & 2.032 \\
25 & -0.49 & 3.138 & 3.383 & 0.1331 & -6.337 & 6.367 & 8.189 \\
30 & -0.47 & 8.668 & 9.347 & 0.3679 & -7.100 & 5.277 & 2.964 \\
\hline
\end{tabular}

rate, Ecorr and Icorr of carbon steel in formation water after added various concentrations. From these results, the corrosion rate reduced as concentration 
increases. The compound (ASC), Table 5 showed the optimum inhibition concentration is $25 \mathrm{ppm}$ with efficiency $98 \%$ whereas at lower (A) concentration a decrease in efficiency can be observed due to its chemical structure, in 5 - 20 ppm has lower solubility and that leads to a less adsorption on metal surface leads to increasing $I_{\text {corr }}$ then reduce its efficiency. In high concentration ( $30 \mathrm{ppm}$ ) the increasing the molecules of (ASC) which have a large chain that caused a steric hindrance on metal surface leads to a difficulty in its adsorption process leads to increasing $I_{\text {corr }}$ then reduce its inhibition efficiency ${ }^{(26)}$. On the other hand, the $\beta c$ of compound (ASC) Table 5 is larger than $\beta c$ of Blank this shows that compound (ASC) behaves as cathodic inhibitor. The efficiency of an inhibitor can be expressed by the measure of this improvement according to the following equation [28] [29].

$$
\mathrm{IE} \%=\frac{\mathrm{CR}^{0}-\mathrm{CR}}{\mathrm{CR}} \times 100
$$

\subsection{Effect Increasing Temperature on Corrosion Rate}

The effect of temperature on inhibition efficiency of the inhibitors on carbon steel (CS) alloy can be studied depending on two principles, the first principle includes increasing the efficiency as it decreases in temperature; this due to physical adsorption mode for the inhibitor on the surface of metal or alloy, and the second principle includes increasing the efficiency as temperature increases; it results from chemical adsorption mode for the inhibitor on the surface of metal or alloy [30] [31] [32].

The present study of the effect of temperature on inhibitor properties and corrosion inhibitor for CS and alloy was studied at range $\left(30^{\circ} \mathrm{C}-50^{\circ} \mathrm{C}\right)$ as is shown in Table 6.

This table showed that this inhibitor have some effects on both, the cathodic and anodic processes. This indicates a modification of the mechanism of cathodic hydrogen evolution as well as anodic dissolution of iron, which suggests that the above inhibitors can be used to inhibit the corrosion process of CS and their suppression of cathodic process by the covering of CS surface with monolayer is due to the adsorbent of inhibitors molecules. It can also be the anodic Tafel constant $(\beta a)$ slopes which has variable values between increasing and decreasing values whereas the decreasing may be described to the changes in charge transfer

Table 6. Effect temperature on corrosion rate of compound (ASC) at optimum value (25 ppm).

\begin{tabular}{|c|c|c|c|c|c|c|c|}
\hline Temp $\left({ }^{\circ} \mathrm{C}\right)$ & $\operatorname{Ecorr}(\mathrm{V})$ & $\begin{array}{c}\operatorname{Icorr}(\mathrm{A}) \\
\mathrm{E}-5\end{array}$ & $\begin{array}{c}\mathrm{CR}(\mathrm{mm} / \text { year }) \\
\mathrm{E}-2\end{array}$ & CR (mpy) & $\begin{array}{c}\beta c(\mathrm{~A} / \mathrm{V}) \\
\mathrm{E}+0\end{array}$ & $\begin{array}{c}\beta \mathrm{a}(\mathrm{A} / \mathrm{V}) \\
\mathrm{E}+0\end{array}$ & $\begin{array}{c}\text { Rct (ohm) } \\
\text { E+3 }\end{array}$ \\
\hline 30 & -0.46 & 0.9178 & 0.9897 & 0.3896 & -6.356 & 4.016 & 2.800 \\
\hline 35 & -0.448 & 2.537 & 2.736 & 1.0771 & -5.888 & 5.515 & 1.013 \\
\hline 40 & -0.413 & 2.604 & 2.808 & 1.1055 & -5.832 & 5.486 & 0.986 \\
\hline 45 & -0.388 & 1.089 & 0.9534 & 0.3753 & -6.146 & 5.923 & 2.906 \\
\hline 50 & -0.409 & 2.128 & 2.294 & 0.9031 & -6.331 & 5.567 & 1.208 \\
\hline
\end{tabular}


resistance. From Table 6, the compound (ASC) showed that the increasing corrosion rate with increasing the temperature as well as increasing in $I_{\text {corr }}$ lead to decreasing Rct and decreasing inhibition efficiency and decreasing in both $\beta \mathrm{a}$ and $\beta c$ with increasing temperature refers to increasing in both anodic and cathodic reactions respectively. The decreasing in inhibition efficiency as temperature decreased can be interpreted due to that desorption is aided by increasing the corrosion. Decreasing in efficiency as temperature increased also results from the decreasing in viscosity of the inhibitor solution then increasing the diffusion of ions in solutions and the decreasing the stability of protective film on metal surface that leads to decrease the activity of the inhibitor. Increasing temperature also increases the diffusion of ions in solutions and decrease the stability of protective film on metal surface which leads to decrease activity of the inhibitor. But at $35.40^{\circ} \mathrm{C}$, the inhibition efficiency increasing as increasing temperature due to the adsorbed process via chemical mode due increasing efficiency with increasing temperature, the shifting in $E_{\text {corr }}$ value toward positive direction [33] [34] [35].

\section{Conclusion}

The inhibition characteristics of compound (ASC) were studied for iron corrosion in formation water. Electrochemical (Tafel polarisation and EFM) method was applied. Polarisation measurements showed that the compound (ASC) acted as cathodic inhibitor. The surfactants chemisorbed on the electrode surface without modifying the mechanism of anodic and cathodic reactions. The cathodic process is activation controlled even in the presence of surfactant. The inhibition efficiency of the surfactants generally increases with the increasing in surfactant concentration. From these results the ammonium sulfonated castor oil (ASC) can be used as anti-corrosion inhibitor for pipeline of crude oil.

\section{References}

[1] Kaesche, H. (2003) Corrosion of Metals Physicochemical Principles and Current Problems. Springer, New York, 05-54.

[2] Valipour, M., Shekarchi, M. and Ghods, P. (2014) Comparative Studies of Experimental and Numerical Techniques in Measurement of Corrosion Rate and Timeto-Corrosion-Initiation of Rebar in Concrete in Marine Environments. Cement \& Concrete Composites, 48, 98-107. https://doi.org/10.1016/j.cemconcomp.2013.11.001

[3] Kim, J., Park, S. and Moon, I. (2009) Corrosion Control Document Database System in Refinery Industry. Chemical Engineering, 27, 1839-1844.

[4] Wu, W., Liu, Z. and Krys, D. (2012) Improving Laser Image Resolution for Pitting Corrosion Measurement Using Markov Random Field Method. Automation in Construction, 21, 172-183. https://doi.org/10.1016/j.autcon.2011.06.002

[5] Alvarez-Pampliega, A., Hauffman, T., Petrova, M., Breugelmansa, T., Muselle, T., Van den Bergh, K., De Strycker, J., Terryn, H. and Hubin, A. (2014) Corrosion Study on Al-Rich Metal-Coated Steel by odd Random Phasemultisine Electrochemical Impedance Spectroscopy. Electrochimica Acta, 124, 165-175. https://doi.org/10.1016/j.electacta.2013.09.159 
[6] Wierzbicka-Miernik, A., Guspiel, J. and Zabdyr, L. (2015) Corrosion Behavior of Lead-Free SAC-Type Solder Alloys in Liquid Media. Erchives of Civil and Mechanical Engineering, 15, 206-213. https://doi.org/10.1016/j.acme.2014.03.003

[7] Gece, G. (2011) Drugs: A Review of Promising Novel Corrosion Inhibitors. Corrosion Science, 53, 3873-3898. https://doi.org/10.1016/j.corsci.2011.08.006

[8] Criado, M. (2015) Handbook of Alkali-Activated Cements, Mortars and Concretes. The Corrosion Behaviour of Reinforced Steel Embedded Inalkali-Activated Mortar, Elsevier Ltd, Amsterdam, 33-72.

[9] Zhang, W., Li, L., Yao, S. and Zheng, G. (2007) Corrosion Protection Properties of Lacquer Coatings on Steel ModiFled by Carbon Black Nanoparticles in NaCl Solution. Corrosion Science, 49, 654-661. https://doi.org/10.1016/j.corsci.2006.06.017

[10] Musa, A.Y., Jalgham, R.T. and Mohamad, A. (2012) Molecular Dynamic and Quantum Chemical Calculations for Phthalazine Derivatives as Corrosion Inhibitors of Mild Steel in $1 \mathrm{M} \mathrm{HCl}$. Corrosion Science, 56, 176-183. https://doi.org/10.1016/j.corsci.2011.12.005

[11] Shen, S., Zuo, Y. and Zhao, X. (2013) The Effects of 8-Hydroxyquinoline on Corrosion Performance of a Mg-Rich Coating on AZ91D Magnesium Alloy. Corrosion Science, 76, 275-283. https://doi.org/10.1016/j.corsci.2013.06.050

[12] Bermudez, M., Carrion, F.J., Martınez-Nicolas, G. and Lopez, R. (2005) ErosionCorrosion of Stainless Steels, Titanium, Tantalum and Zirconium. Wear, 258, 693700. https://doi.org/10.1016/j.wear.2004.09.023

[13] Meresht, E.S., Farahani, T.S. and Neshati, J. (2012) 2-Butyne-1, 4-diol as a Novel Corrosion Inhibitor for API X65 Steel Pipeline in Carbonate/Bicarbonate Solution. Corrosion Science, 54, 36-44. https://doi.org/10.1016/j.corsci.2011.08.052

[14] Blankson, M.A. and Erdem, S. (2015) Comparison of the Effect of Organic and Inorganic Corrosion Inhibitors on the Rheology of Self-Compacting Concrete. Construction and Building Materials, 77, 59-65. https://doi.org/10.1016/j.conbuildmat.2014.12.032

[15] Yang, J., Peng, J., Shen, Z., Jia, J. and Zhang, F. (2006) Corrosion Protection of Iron in Water by Activated Carbon Fiber (ACF). Carbon, 44, 19-26. https://doi.org/10.1016/j.carbon.2005.07.006

[16] Reclaru, L., Ziegenhagen, R., Unger, R.E., Eschler, P.Y. and Constantin, F. (2014) New Generation Super Alloy Candidates for Medical Applications: Corrosion Behavior, Cation Release and Biological Evaluation. Materials Science and Engineering, 45, 411-420. https://doi.org/10.1016/j.msec.2014.09.027

[17] Sun, H., Wang, H. and Meng, F. (2011) Study of Corrosion Protection of the Composite Films on A356 Aluminum Alloy. Rare Earths, 29, 991-996. https://doi.org/10.1016/S1002-0721(10)60584-4

[18] Schweitzer, P.A. (2007) Corrosion Engineering Handbook. Chapter 3, CRC Press, Boca Raton.

[19] Zhang, J. (2009) A Review of Steel Corrosion by Liquid Lead and Lead-Bismuth. Corrosion Science, 51, 1207-1227. https://doi.org/10.1016/j.corsci.2009.03.013

[20] Sun, C., Hui, R., Qu, W. and Yick, S. (2009) Progress in Corrosion Resistant Materials for Supercritical Water Reactors. Corrosion Science, 51, 2508-2523. https://doi.org/10.1016/j.corsci.2009.07.007

[21] Zhou, Q., Wang, Y., Wu, H., Zhong, Q. and Jiang, J. (2012) Preparation of Passive $\mathrm{Cu}-\mathrm{Ni}-\mathrm{Fe}$ Coating on Low-Carbon Steel for Improving Corrosion Resistance. Surface \& Coatings Technology, 207, 503-507. https://doi.org/10.1016/j.surfcoat.2012.07.060 
[22] Durrieu, M. and Havre, L. (1992) Us Patent. 5, 154, 857.

[23] Hobson, G.D. (1988) Modern Petroleum Technology. Vol. 2, Applied Science Publishers, LTD, Halsted Press, New York, 586.

[24] Lorenz, H. and Martin, H. (1976) US Patent. 3, 974, 220.

[25] Kirk, O. (1988) Encyclopedia of Chemical Technology. Vol. 19, John Wiley \& Sons, New York.

[26] Gauglitz, G. and Vo-Dinh, T. (2003) Handbook of Spectroscopy. Wiley-VCH Verlag GmbH \& Co. KGaA, Weinheim. https://doi.org/10.1002/3527602305

[27] Stuart, B. (2004) Infrared Spectroscopy: Fundamentals and Applications. Chapter 4, Wiley \& Sons, Ltd., New York. https://doi.org/10.1002/0470011149

[28] Ashraful, A.M., Masjuki, H.H., Kalam, M.A., Rashedul, H.K., Sajjad, H. and Abedin, M.J. (2014) Influence of Anti-Corrosion Additive on the Performance, Emission and Engine Component Wear Characteristics of an IDI Diesel Engine Fueled with Palm Biodiesel. Energy Conversion and Management, 87, 48-57.

[29] Chaudhary, A.S., Jin, J., Chen, W., Tai, P.C. and Wang, B. (2015) Design, Syntheses and Evaluation of 4-oxo-5-cyano Thiouracils as SecA Inhibitors. Bioorganic \& Medicinal Chemistry, 23, 105-117.

[30] Shaban, S.M., Aiad, I., El-Sukkary, M.M., Soliman, E.A. and El-Awady, M.Y. (2015) Evaluation of Some Cationic Surfactants Based on Dimethylaminopropylamine as Corrosion Inhibitors. Industrial and Engineering Chemistry, 21, 1029-1038.

[31] Zhua, Y., Zhuang, J. and Zeng, X. (2014) Mechanism of $\left(\mathrm{NH}_{4}\right) \mathrm{S}_{2} \mathrm{O}_{8}$ to Enhance the Anti-Corrosion Performance of MoCe Inhibitor on X80 Steel in Acid Solution. Applied Surface Science, 313, 31-40.

[32] Mourya, P., Banerjee, S. and Singh, M.M. (2014) Corrosion Inhibition of Mild Steel in Acidic Solution by Tagetes Erecta (Marigold Flower) Extract as a Green Inhibitor. Corrosion Science, 85, 352-363.

[33] Obot, I.B., Obi-Egbedi, N.O. and Umoren, S.A. (2009) Adsorption Characteristics and Corrosion Inhibitive Properties of Clotrimazole for Aluminium Corrosion in Hydrochloric Acid. International Journal of Electrochemical Science, 4, 863-877.

[34] Ahmed, R.A., Farghali, R.A. and Fekry, A.M. (2012) Study for the Stability and Corrosion Inhibition of Electrophoretic Deposited Chitosan on Mild Steel Alloy in Acidic Medium. International Journal of Electrochemical Science, 7, 7270-7282.

[35] Roberge, P.R. (2000) Handbook of Corrosion Engineering. Chapter 10, Corrosion Inhibitors. McGraw-Hill, New York.

[36] Baddini, A.L.D.Q., Cardoso, S.P., Hollauer, E. and Gomesc, J.A.D.C.P. (2007) Statistical Analysis of a Corrosion Inhibitor Family on Three Steel Surfaces (Duplex, Super-13 and Carbon) in Hydrochloric Acid Solutions . Electrochimica Acta, 53, 434-446. 
Submit or recommend next manuscript to SCIRP and we will provide best service for you:

Accepting pre-submission inquiries through Email, Facebook, LinkedIn, Twitter, etc. A wide selection of journals (inclusive of 9 subjects, more than 200 journals)

Providing 24-hour high-quality service

User-friendly online submission system

Fair and swift peer-review system

Efficient typesetting and proofreading procedure

Display of the result of downloads and visits, as well as the number of cited articles Maximum dissemination of your research work

Submit your manuscript at: http://papersubmission.scirp.org/

Or contact eng@scirp.org 